Rev. Bras. Saúde Prod. Anim., Salvador, v.13, n.3, p.825-837 jul./set., 2012 http://www.rbspa.ufba.br ISSN 15199940

\title{
Aspectos produtivos e sanitários do rebanho leiteiro nas propriedades do sudoeste da Bahia ${ }^{1}$
}

\author{
Production aspects and dairy herd health in dairy farms located in southwestern of Bahia
}

\author{
PATÊS, Neusete Maria da Silva ${ }^{2} *$; FIGUEIREDO, Mauro Pereira de $^{2}$; PIRES, \\ Aureliano José Vieira ${ }^{2}$; CARVALHO, Gleidson Giordano Pinto de ${ }^{3}$; SILVA, Fabiano \\ Ferreira da ${ }^{2}$; FRIES, Daniela Deitos ${ }^{2}$; BONOMO, Paulo $^{2}$; ROSA, Raul Castro Carriello ${ }^{2}$
}

\author{
${ }^{1}$ Parte da tese da primeira autora. \\ ${ }^{2}$ Universidade Estadual do Sudoeste da Bahia, Programa de Pós-Graduação em Zootecnia, Itapetinga, \\ Bahia, Brasil. \\ ${ }^{3}$ Universidade Federal da Bahia, Escola de Medicina Veterinária e Zootecnia, Departamento de \\ Zootecnia, Salvador, Bahia, Brasil. \\ *Endereço para correspondência: neuset.maria@yahoo.com.br
}

\section{RESUMO}

O leite é um alimento de grande importância nutricional. Além disso, a atividade leiteira pode ser destacada pelo desenvolvimento econômico e social que promove nas propriedades rurais. Dessa forma, objetivou-se, neste trabalho, caracterizar a produção de leite e o manejo sanitário dos animais de propriedades da bacia leiteira da região sudoeste da Bahia. A metodologia proposta foi composta pela aplicação de um questionário, constituído de questões objetivas, a uma amostra de 94 produtores, que fornecem leite para cooperativas ou laticínios da região, cadastrados no diagnóstico inicial das fazendas do programa Geraleite. Os dados obtidos foram importantes para conhecer e comparar o perfil de fazendas leiteiras nessa região. Com a pesquisa, constatou-se que $54,7 \%$ dos produtores não fazem anotações zootécnicas e 64,9\% não fazem anotações relacionadas à parte econômica. Dos entrevistados, $82 \%$ praticam nas propriedades uma ordenha e $18 \%$ duas ordenhas por dia, a monta natural não controlada foi o manejo reprodutivo mais utilizado. A média geral da produção de leite nas fazendas foi de 1125 litros de leite/vaca/ano e 3,1 litros/vaca/dia. Essa baixa produtividade deve-se, principalmente, à deficiência tecnológica, animais não especializados e à falta de assistência técnica nas fazendas.

Palavras-chave: bovino, produção leiteira, manejo sanitário, sistema de criação.

\section{SUMMARY}

Milk is a food of great nutritional importance. In addition, the dairy can be highlighted by the economic and social development that promotes in the rural properties. Thus, the objective of this study was to characterize milk production and animal health management of properties in the dairy region of the southwestern region of Bahia. The methodology proposed is made by applying a questionnaire with objective questions, using a sample of 94 producers participating in the research that provide milk for dairy cooperatives and dairy in the region registered in the preliminary farm diagnosis in program Geraleite. The data obtained are important to know and to compare the profile of dairy farms in this region, $54.7 \%$ of producers did not take husbandry notes and $64.9 \%$ did not take notes related to the economics. Of the respondents $82 \%$ make one milking and $18 \%$ two milkings per day in properties, the natural mating uncontrolled was the reproductive management more used. The average milk production on farms was 1125 liters of milk /cow/year and 3.1 liters/cow/day. This low productivity is due mainly to technological deficiency, non specialized animals and lack of technical assistance in the farms.

Keywords: breeding system, cattle, pasture. 


\section{INTRODUÇÃOO}

A pecuária leiteira na região sudoeste da Bahia é uma das atividades predominantes das pequenas e médias propriedades rurais. Em sua maioria, os pastos constituem-se na principal fonte de alimento para o rebanho, especialmente, compostos de gramíneas tropicais. A produção de leite a pasto busca reduzir custos de produção em relação ao uso de concentrados. Nessa óptica, devem-se adotar estratégias de manejo do pastejo de acordo com os pastos em cada época do ano.

$\mathrm{O}$ aumento da produtividade leiteira é de grande interesse de produtores, técnicos e pesquisadores e está na dependência de fatores genéticos, sanitários, ambientais, nutricionais e suas interações (TEIXEIRA et al., 2010). Dessa forma, a baixa produtividade dos rebanhos deve estar associada à qualidade genética dos animais, à alimentação e ao nível tecnológico aplicado pelos pecuaristas nas unidades produtivas.

O estado da Bahia possui o terceiro maior rebanho de gado leiteiro do Brasil, mas ocupa a $23^{a}$ posição em produtividade por vaca ordenhada, produzindo 950 milhões de litros de leite/ano e consumindo 1,6bilhões de litros. Eliminar esse déficit de 650 milhões de litros de leite é o grande desafio da pecuária leiteira baiana (SEAGRI, 2010). Nesse contexto, com o intuito de reverter essa situação, é necessário desenvolver um diagnóstico para caracterizar os sistemas de produção de leite em cada região da Bahia.

Oliveira et al. (2007) desenvolveram um trabalho sobre os sistemas de produção de leite, no extremo sul baiano, e verificaram que os indicadores-referência, obtidos para a região, diferem dos índices globais divulgados pelo setor. Isso indica a necessidade de estudos regionalizados para caracterizar os sistemas de produção de leite, que identifiquem e quantifiquem, periodicamente, os índices, sem deixar de considerar o caráter dinâmico inerente ao ambiente de produção e a elevada diversidade sócio-econômica, cultural e edafo-climática.

Assim, objetivou-se, neste trabalho, traçar um diagnóstico da atividade leiteira na região sudoeste da Bahia, de modo a abordar os diversos aspectos em torno da produção primária e destacar a tecnologia empregada na produção de leite e a condição sanitária à qual os animais estavam sujeitos.

\section{MATERIAL E MÉTODOS}

O estudo foi realizado na região econômica do sudoeste da Bahia, Brasil, no período de fevereiro a dezembro de 2010. De acordo com a SEI (2010) Superintendência de Estudos Econômicos e Sociais da Bahia, o sudoeste baiano é composto por 39 municípios, a saber: Anagé, Barra do Choça, Belo Campo, Boa Nova, Bom Jesus da Serra, Caatiba, Caetanos, Cândido Sales, Caraíbas, Cravolândia, Encruzilhada, Firmino Alves, Ibicuí, Iguaí, Irajuba, Itambé, Itapetinga, Itaquara, Itarantim, Itiruçu, Itororó, Jaguaquara, Jequié, Lafaiete Coutinho, Lajedo do Tabocal, Macarani, Maiquinique, Manoel Vitorino, Maracás, Mirante, Nova Canaã, Planaltino, Planalto, Poções, Potiraguá, Ribeirão do Largo, Santa Inês, Tremedal e Vitória da Conquista. Está localizado entre as coordenadas $13^{\circ} 02^{\prime}$ a $16^{\circ} 00^{\prime}$ de Latitude Sul e $39^{\circ}$ a $41^{\circ} 49^{\prime}$ de Longitude Oeste, e é uma das 15 regiões econômicas do estado proposta pela Superintendência de Estudos Econômicos e Sociais da Bahia SEI - BA.

Foram realizados contatos com os laticínios e cooperativas de leite em funcionamento na região em estudo para 
definir o público-alvo da pesquisa. A seguir, realizaram-se viagens a campo para o reconhecimento da região, identificação do uso dos sistemas de produção e tipo de exploração do sistema leiteiro. O estudo foi realizado a partir de uma população referencial, representada pelos produtores de leite dos municípios da região, cadastrados na fase inicial do programa Geraleite. O projeto Geraleite é promovido pela Federação da Agricultura do Estado da Bahia (FAEB), pelo Serviço Nacional de Aprendizagem Rural (SENAR), pelo Serviço Brasileiro de Apoio às Micros e Pequenas Empresas SEBRAE e pela Universidade Estadual do Sudoeste da Bahia (UESB), por meio da sua Fundação (FADCT).

Antes de constituir a amostra, foi realizado um reconhecimento das propriedades rurais, a partir do qual foram selecionadas 94 propriedades, com áreas entre 10 a 1280 hectares. Primeiramente, foram elaboradas questões, cuja abordagem estava de acordo com o intuito da pesquisa. Posteriormente, aplicaram-se 10 questionários para servirem como base de correção das perguntas integrantes, assim, essa etapa funcionou como pré-teste da pesquisa. Após aplicação dos questionários-teste, realizaram as devidas correções e procederam-se as indagações por meio de entrevistas realizadas diretamente com os produtores de leite nas suas respectivas propriedades. Procurou-se visitar as propriedades localizadas em grupos por "linhas de leite", a fim de promover maior facilidade de acesso aos terrenos, de modo a agilizar os procedimentos e reduzir o tempo para a coleta dos dados junto aos produtores.

Foram aplicados 94 questionários, que corresponderam a $66,2 \%$ do total de produtores da região, cadastrados no Geraleite, que fornecem leite para os laticínios e cooperativas, escolhidos aleatoriamente para participarem da pesquisa. Logo, os dados foram coletados através da aplicação de questionários elaborados com perguntas objetivas, redigidas em linguagem acessível ao produtor rural, com a possibilidade em algumas perguntas terem mais de uma resposta, informação que foi repassada aos entrevistados.

Nas perguntas com possibilidade de múltiplas respostas, o produtor poderia escolher, dentro das opções, uma alternativa aberta, além de ser ouvido atentamente nos seus desabafos com relação à atividade leiteira. Os questionamentos foram abordados com perguntas relacionadas à tecnologia para obtenção e produção de leite com foco em sanidade, ordenha higiênica, escrituração zootécnica (parição, cobrição, controle leiteiro, pesagem dos animais, taxa de nascimento, taxa de mortalidade e vacinação), econômica (despesas, receitas, custos de produção e leite vendido), manejo reprodutivo e infraestrutura da propriedade.

Com as informações obtidas através da aplicação do questionário, desenvolveu-se uma planilha com as variáveis desejáveis para o estudo para atender aos objetivos propostos, em que os produtores foram enumerados de 1 a 94 na primeira coluna e nas demais colunas foram registradas as informações obtidas pelas respectivas respostas. Após a elaboração da planilha, procedeu-se a análise dos dados pelo programa software Microsoft Excel for Windows e sistematizados em gráficos e tabelas ou percentuais. Como forma de estabelecer uma compreensão mais esclarecedora das informações colhidas, optou-se por uma análise estatística descritiva (LUIZ \& SILVEIRA, 2000; FERREIRA et al., 2005). 


\section{RESULTADOS E DISCUSSÃO}

Os resultados obtidos com esta pesquisa realizada na região sudoeste da Bahia revelaram uma agropecuária de caráter tradicional, com pecuária extensiva. Os animais eram de sangue zebuíno e sua maioria mestiça, por serem mais adaptados às características da região, mas foram encontrados alguns puros da raça Holandesa. Resultado semelhante foi verificado por Fernandes et al. (2012) que, ao estudarem sistemas de produção de leite na mesma região, constataram a predominância do agrupamento genético mestiço (Zebuínos x Taurinos).

Observou-se que o sistema de ordenha adotado pela totalidade dos entrevistados $(93,6 \%)$ era realizado pela manhã, de forma manual, e 6,4\% adotavam o sistema de ordenha mecânica. Nas propriedades leiteiras, predominava $\mathrm{o}$ sistema de ordenha manual, característica que reflete a realidade da produção de leite regional e, possivelmente, indica o baixo volume de produção, o que levava os produtores a não investirem em equipamento como a ordenhadeira mecânica; outra razão é o baixo custo pago à mão-de-obra do vaqueiro na região, o que facilita manter a tradição da ordenha manual.

Quanto à frequência diária de ordenhas, $82,0 \%$ dos entrevistados praticavam nas propriedades uma ordenha e $18,0 \%$ duas ordenhas por dia. Foi encontrado um maior percentual da prática de uma ordenha diária, número que pode explicar a baixa produtividade e o baixo volume de produção. Além disso, esses animais possuem uma baixa especialização para leite, e o sistema extensivo em que são criados possuem forragens de baixa qualidade que não conseguem suprir suas demandas nutricionais.

Verificou-se que os locais onde eram realizadas as ordenhas nas propriedades tratavam-se principalmente de currais, com instalações simples, com um percentual de 64,9\%, seguido de estábulos simples, com 24,5\% (Figura 1). Provavelmente, esses dois modelos prevaleçam pelo menor custo das instalações e pela falta de investimento em tecnologia na infraestrutura das propriedades.

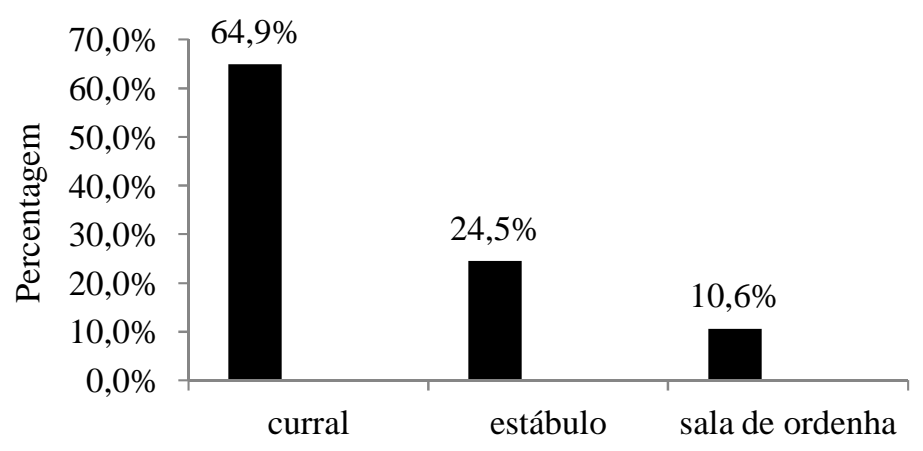

Figura 1. Percentual do local onde é realizada a ordenha nas propriedades leiteiras

Quanto às ordenhas realizadas em sala adequadas de ordenha, houve uma menor participação, com $10,6 \%$ nas propriedades, o que constata, assim, que o produtor não dispõe de capital financeiro para melhorar a infraestrutura e a produtividade na sua unidade. Esses resultados foram semelhantes aos obtidos 
por Winck \& Thaler Neto (2012), em estudo realizado em Santa Catarina, os quais observaram que $94 \%$ das propriedades realizavam ordenhas em estábulo convencional e apenas $6 \%$ possuíam sala de ordenha.

O local da ordenha deve ser o mais higiênico possível, pois o manejo preventivo ajuda na qualidade do leite. $\mathrm{O}$ procedimento classificado como adequado para ordenha deve estar de acordo com as seguintes recomendações: sala limpa, antes da ordenha dos animais; separação das vacas com mastite clínica ou subclínica crônica para ordenha posterior; condução das vacas de forma calma; desinfecção das tetas pré-ordenha; secagem das tetas com toalha de papel descartável e individual; realização do teste de caneca de fundo preto, diariamente, para identificação de mastite clínica; realização do teste de CMT (California Mastitis Test), mensalmente, para detecção de mastite subclínica; imersão das teteiras em solução desinfetante entre a ordenha de um animal e outro; desinfecção das tetas e alimentação dos animais depois da ordenha concluíram Zanela et al. (2006).

Deve-se levar em consideração a qualidade da água utilizada na lavagem do úbere, pois, quando intensamente contaminada por coliformes, pode ser responsabilizada por surtos de mastite (AMARAL et al., 2004). Daí a importância de se utilizar nas fazendas leiteiras água de boa qualidade.

Quanto ao manejo reprodutivo utilizado nas propriedades leiteiras da região, verificou-se como principal, a monta natural sem controle, prática informada por $65,2 \%$ dos entrevistados, de modo a caracterizar-se como o sistema tradicional de produção mais utilizado pelos produtores, como verificado na Tabela 1. Os investimentos em tecnologias de manejo reprodutivo, nesse tipo de sistema, são baixos, os animais são criados juntos com a presença constante de touros, sem nenhum critério de seleção, o que dificulta o melhoramento genético no rebanho. Ao examinar esses resultados e compará-los com os da Tabela 3, nota-se que eles indicam que, com adoção de manejo reprodutivo inadequado, obtêm-se resultados abaixo do ideal para a produtividade.

Por outro lado, $15,7 \%$ dos produtores adotam a monta controlada e $19,1 \%$ dos produtores utilizam inseminação artificial em suas propriedades. Essa tecnologia possibilita melhorias na qualidade genética do rebanho.

Tabela 1. Manejo reprodutivo utilizado nas propriedades leiteiras, no sudoeste da Bahia

\begin{tabular}{lc}
\hline Tipo de cobrição & $\begin{array}{c}\% \text { das } \\
\text { propriedades }\end{array}$ \\
\hline Inseminação artificial & 19,1 \\
Monta natural controlada & 15,7 \\
Monta natural sem controle & 65,2 \\
\hline Critério para cobrir as novilhas & \\
\hline Idade & 17,7 \\
Peso & 21,0 \\
Idade/peso & 9,2 \\
Sem utilizar critérios & 52,1 \\
\hline
\end{tabular}

Neves et al. (2011) estudaram a caracterização dos sistemas de produção de leite em 28 propriedades, no perímetro irrigado de Petrolina/PE, e verificaram que o manejo reprodutivo mais comum naquela região foi o sistema de monta natural em $96,4 \%$ das propriedades e 3,6\% inseminação artificial. Esses dados demonstram que o sistema de monta natural ainda prevalece em muitas propriedades leiteiras.

Quando indagados se adotavam algum critério para cobrição das novilhas, $52,1 \%$ dos entrevistados responderam não ter critérios. Entretanto, $21 \%$ dos produtores utilizavam um dos parâmetros recomendados, o peso, de acordo com a 
raça utilizada. O peso vivo para cobrição das novilhas varia de acordo com a raça, cujo valor mínimo se expressa em $340 \mathrm{~kg}$ para a raça Holandesa, $330 \mathrm{~kg}$ para a Pardo-Suíço, $230 \mathrm{~kg}$ para a Jersey, $320 \mathrm{~kg}$ para as mestiças Holandês x Zebu e 280 $\mathrm{kg}$ para as mestiças Jersey $\mathrm{x}$ Zebu (EMBRAPA, 2011). Já 17,7\% preferem ter como critério a idade, e 9,2\% usam, simultaneamente, os dois critérios.

Na Figura 2, observam-se os percentuais encontrados nas propriedades, quanto aos controles zootécnicos e econômicos. Esses parâmetros de suma importância para o sucesso da atividade leiteira, pois é com base neles que o produtor terá dados reais (cobrição, parição, vacinação, controle de leite, receitas, despesas, insumos, etc.) com os quais poderá avaliar a sua produção leiteira, juntamente com o seu rebanho. Nota-se que $54,7 \%$ dos produtores não faziam anotações zootécnicas e $64,9 \%$ não faziam anotações relacionadas à parte econômica. Esses números são preocupantes para o setor, pois não há um planejamento das ações desenvolvidas dentro da propriedade, o que pode acarretar prejuízos financeiros, de modo a fazer com que o produtor aumente os custos com a produção ou se afaste da atividade leiteira.

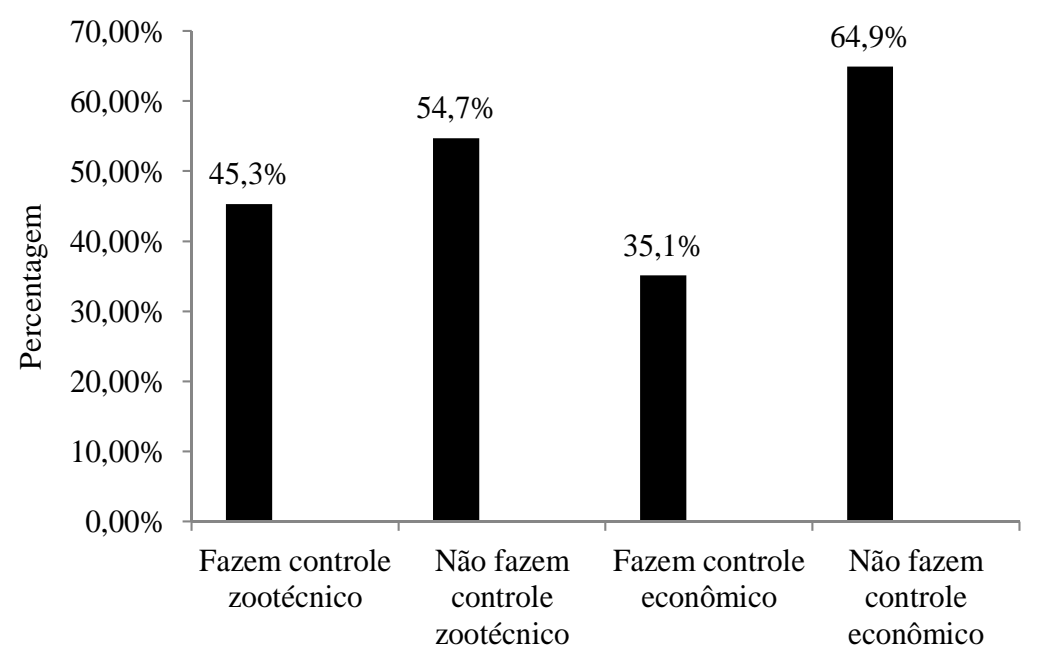

Figura 2. Percentual de propriedades que fazem controle zootécnico e econômico

A qualidade do leite está diretamente relacionada às condições sanitárias do rebanho, ao manejo nutricional e ao manejo de ordenha, os quais devem seguir os preceitos de boas práticas de produção (PONTES NETTO et al., 2005). Conforme informações dos entrevistados nesta pesquisa, entre as doenças que mais acometem o rebanho destacam-se a tristeza parasitária bovina $(37,2 \%)$, decorrente da incidência de carrapato dos bovinos na região; a mastite $(24,5 \%)$ e a diarreia em bezerros $(3,0 \%)$, conforme a Figura 3.

A tristeza parasitária é uma doença infecciosa e parasitária dos bovinos, causada por um protozoário do gênero babesia (babesiose) e por rickettsia do gênero Anaplasma (Anaplasmose), transmitida aos animais pelo carrapato dos bovinos. A sintomatologia clínica da tristeza parasitária se manifesta através de 
febre, anemia, hemoglobinúria, icterícia, inapetência, pêlos arrepiados e prostração. Quanto à mastite, é uma doença causada por bactérias dos gêneros estreptococos e estafilococos, além das eterobactérias Escherichia coli.

O produtor deve adotar práticas corretas de manejo sanitário para o seu rebanho e manter uma boa higiene, principalmente, durante as ordenhas, que deve ser o ponto de partida para assegurar a eficiência produtiva e prevenir seu rebanho de enfermidades que provocam grandes perdas econômicas na pecuária, com a redução da produção de leite e carne. A ocorrência de diarreia em bezerros pode ser influenciada por fatores de manejo e higiene. Essa afecção acomete animais nos primeiros dias de vida e causa importantes perdas econômicas, principalmente, por retardo de crescimento e mortalidade.

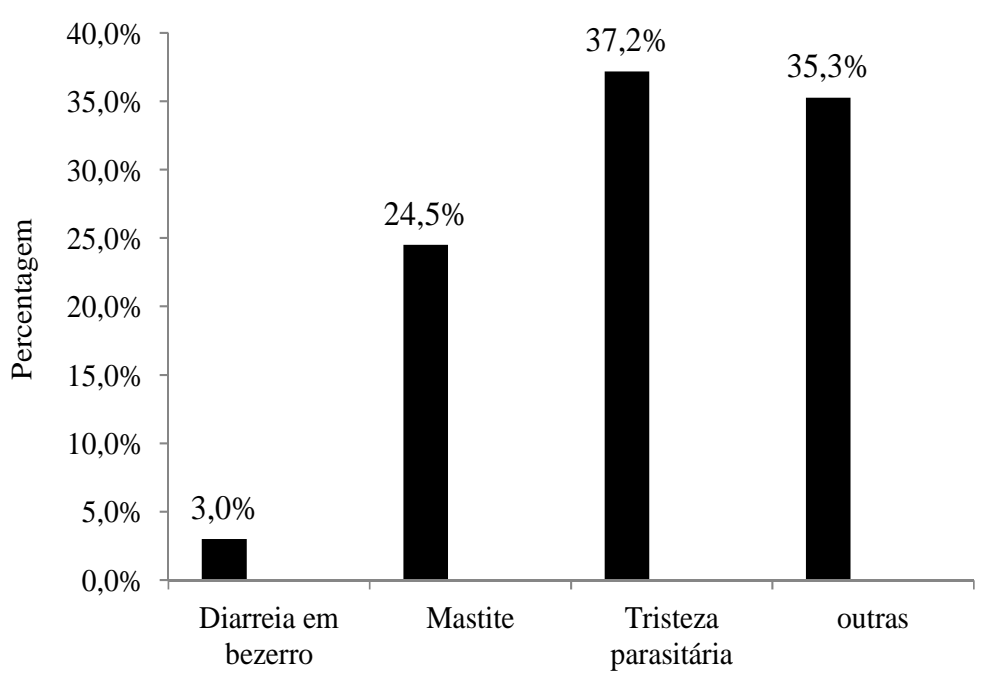

Figura 3. Percentual de doenças que acomete o rebanho nas propriedades leiteiras do sudoeste da Bahia

As medidas preventivas através de vacinas das principais doenças encontram-se na Figura 4. Observa-se que em todas as propriedades leiteiras realizavam vacinação contra febre aftosa $(100,0 \%)$, brucelose $(96,2 \%)$, clostridiose $(82,6 \%)$, paratifo $(22,1 \%) \mathrm{e}$ raiva $(63,5 \%)$. Em todas as propriedades que participaram da entrevista, de modo geral, era praticado o controle de ectoparasitas e endoparasitas nos animais, cujo princípio ativo mais utilizado era a ivermectina. $\mathrm{O}$ manejo sanitário bem conduzido, através do controle e prevenção de algumas enfermidades em que o produtor respeita e cumpre o calendário de vacinas de sua região, faz com que o seu produto ganhe credibilidade no mercado e evita prejuízos econômicos.

Devido à preocupação com os casos de mastite que ocorrem na região e, para prevenir o rebanho leiteiro, os entrevistados foram questionados se realizavam algum teste para detecção de mastite nos seus animais (Figura 5). 
Rev. Bras. Saúde Prod. Anim., Salvador, v.13, n.3, p.825-837 jul./set., 2012 http://www.rbspa.ufba.br ISSN 15199940

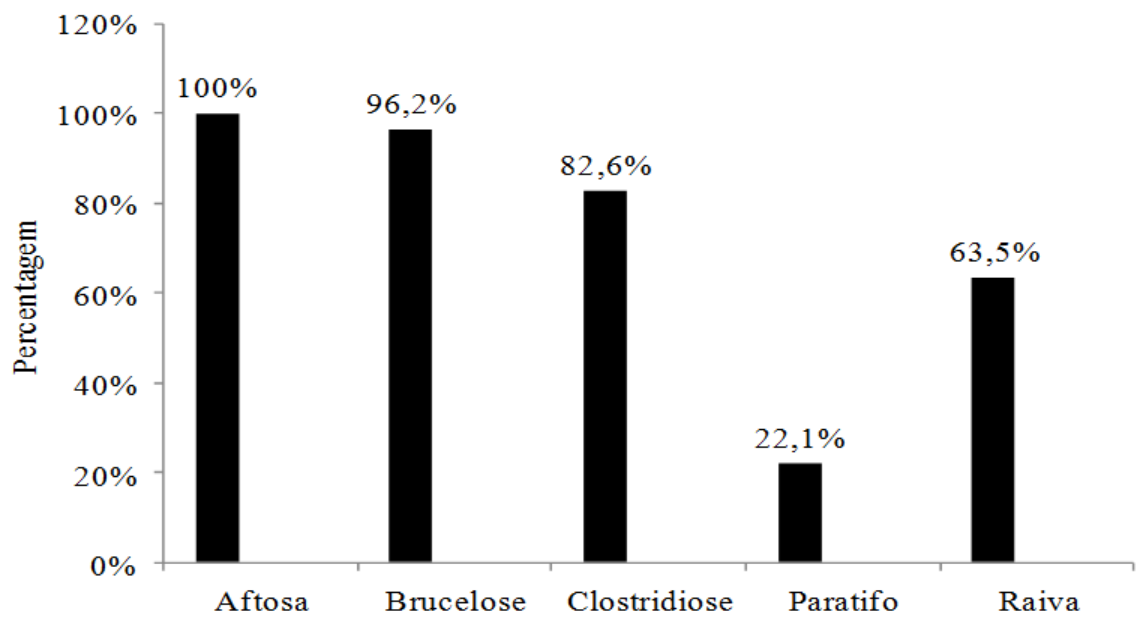

Figura 4. Percentual das principais vacinas utilizadas nas propriedades leiteiras no sudoeste da Bahia

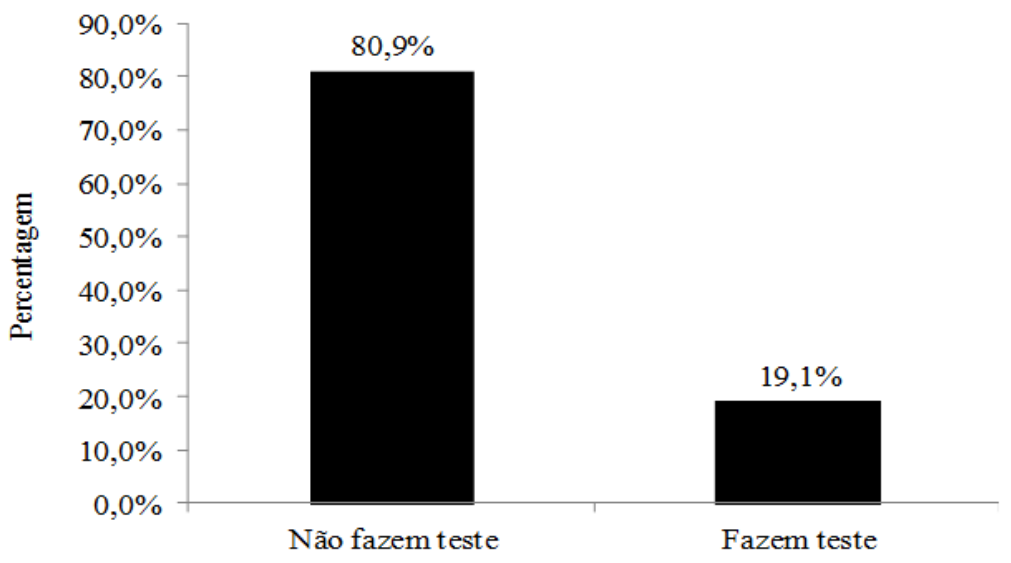

Figura 5. Percentual das propriedades leiteiras que realizam teste para verificar a presença de mastite

O resultado foi contundente: a maioria dos entrevistados $80,9 \%$, afirmaram que não realizavam o teste (Figura 5). Alguns justificaram que não faziam por falta de conhecimento das práticas que são utilizadas, tais como o teste da caneca de fundo preto, que é realizado com os primeiros jatos de leite, quando observado na caneca a presença de grumos ou pus, a vaca pode ter mastite clínica; já para detectar a mastite sub-clínica caracterizada pela redução de leite sem sintomatologia aparente, com ausência dos sinais visíveis, é realizado o Califórnia Mastite teste - CMT (ZANELA et al., 2006).

É necessário que a infraestrutura e os equipamentos utilizados nas propriedades leiteiras ofereçam a mínima condição de conforto para o bem-estar dos animais e possam dar suporte à produção. Ao analisar a Tabela 2, nota-se que os produtores se preocupavam com os equipamentos essenciais para facilitar o 
trabalho nas fazendas. O pulverizador é encontrado em $58,8 \%$ das propriedades; a picadeira de forragem em 53,1\%, essencial na execução do manejo alimentar na entressafra das pastagens; carroças em $45,0 \%$; trator em $28,1 \%$ e o tanque de expansão em $26,4 \%$, o qual foi encontrado em poucas propriedades. Esse baixo percentual deve ser considerado com reservas, pois, trata-se de fazendas que desenvolvem a atividade leiteira e necessitam desse equipamento para manter o leite resfriado a temperatura ideal. Porém, alguns alegaram não o possuí-lo pelo fato de o caminhão passar todos os dias, após a ordenha e fazer a coleta do leite a granel.

Tabela 2. Percentual dos equipamentos utilizados nas propriedades leiteiras

\begin{tabular}{lc}
\hline Item & $\begin{array}{c}\% \text { das } \\
\text { propriedades }\end{array}$ \\
\hline Carroça & 45,0 \\
Desintegrador de forragem & 53,1 \\
Pulverizador & 58,8 \\
Trator & 28,1 \\
Tanque de expansão & 26,4 \\
\hline
\end{tabular}

Para o abrigo dos bezerros, observa-se que as fazendas que não possuíam bezerreiro apresentaram os maiores percentuais $76,6 \%$. Para as propriedades que possuíam bezerreiro coletivo o percentual foi de $20,2 \%$ e, para os individuais, manejo mais adequado, foi encontrado somente em 3,2\% das propriedades (Figura 6). Essa medida adotada visa evitar aglomeração dos animais, diminuir a transmissão de doenças e facilitar a higiene do local. A forma de aleitamento dos bezerros lactantes nessas propriedades era feita da seguinte maneira, 97\% recebem de forma natural e $3 \%$ artificialmente, por meio de baldes.

Com relação às atividades exploradas, na Figura 7, observa-se que, nas propriedades, a principal atividade é a pecuária leiteira. Entretanto, pelo fato da venda exclusiva do leite não conseguir pagar as despesas das propriedades, existem também a venda de animais e a venda de cacau. Nesta, porém, os produtores não fazem maiores investimentos, devido ao receio da doença "vassoura de bruxa", que está presente nestes cultivos na região.

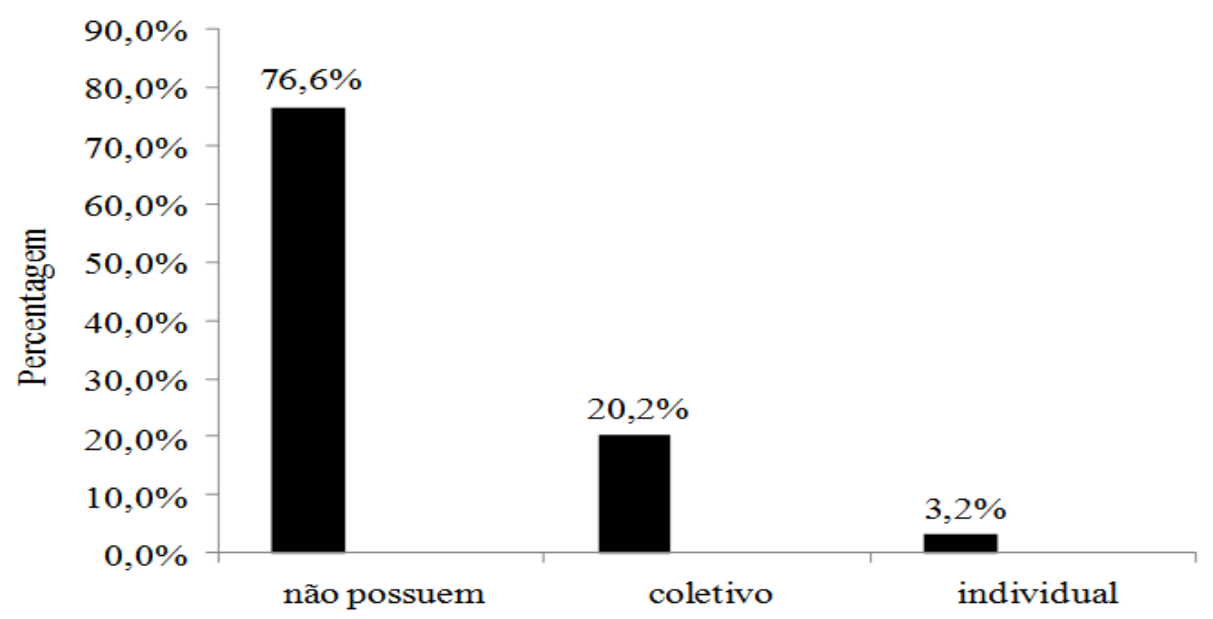

Figura 6. Percentual de bezerreiro nas propriedades leiteiras, no sudoeste da Bahia 


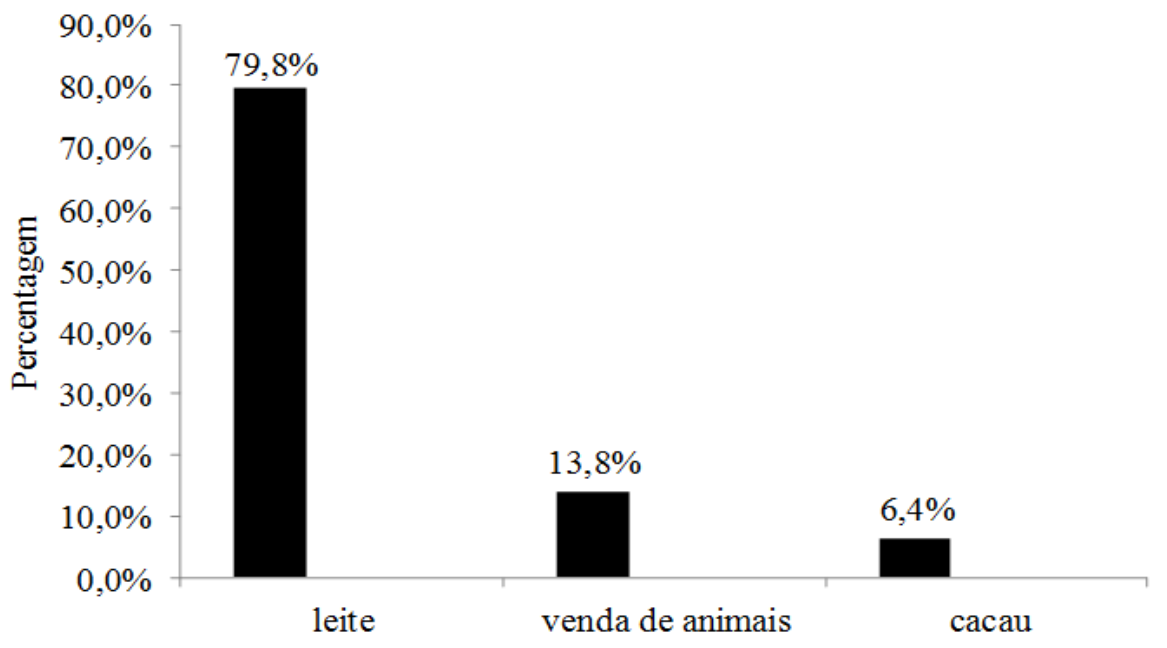

Figura 7. Percentual das principais fontes de renda dos produtores no sudoeste da Bahia

Oaigen et al. (2011) avaliaram os sistemas de produção de bovinos de corte em 29 propriedades na região norte do Brasil e verificaram que a principal atividade desenvolvida em parceria com a bovinocultura de corte foi a bovinocultura leiteira, devido às fortes bacias leiteiras existentes nos Estados do Pará e Rondônia, com a participação de 20,7\% das propriedades. Nesse contexto, verifica-se que é necessário o setor leiteiro se reorganizar e envolver toda cadeia a fim de aumentar a sua competitividade e qualidade do produto. Quanto à produção de leite, foram encontrados os valores médios de $716 \mathrm{~L} / \mathrm{ha} / \mathrm{ano}$ ao ano e $1125 \mathrm{~L} / \mathrm{ha} / \mathrm{ano}$. A produção de litros de leite por vaca, o valor médio encontrado na região sudoeste da Bahia foi de 3,1 L/ha/ano (Tabela 3). Essa baixa produtividade deve-se, principalmente, à deficiência tecnológica, às vacas não especializadas e à falta de assistência técnica nas fazendas.

Tabela 3. Produção de leite (litros/ha/ano), produção média (litros/vaca/ano) e (litros/vaca/dia) nas propriedades leiteiras no sudoeste da Bahia

\begin{tabular}{lcc}
\hline Item & Unidade & Média \\
\hline Produtividade por hectare/ano & L/ha/ano & 716 \\
Produtividade por vaca/ano & L/vaca/ano & 1125 \\
Produtividade por total de vacas & L/vaca/dia & 3,1 \\
\hline
\end{tabular}

Percebeu-se que a atividade leiteira é a principal fonte de renda dos produtores, porém, os dados obtidos nas propriedades em estudo indicaram uma participação considerável da pecuária de corte na caracterização leiteira da região, que justifica os dados apresentados na Figura
7, pelo fato dos produtores, além de comercializarem o leite, também vendem bezerros para incrementar a receita. Esses resultados são compatíveis com os de Azevedo et al. (2011) que, ao analisarem o perfil de propriedades leiteiras com produção mista no norte de Minas Gerais, 
também verificaram que o menor preço pago ao leite poderia ser um dos fatores relacionados à opção de algumas propriedades em também produzir bezerros de corte, pois muitas propriedades produtoras de leite, paralelamente, adotam um sistema de produção de animais de corte, o que gera grande dificuldade para se definir um padrão de produção de leite ou de corte.

$\mathrm{Na}$ realidade, esse fato parece indicar uma forte tradição cultural, uma vez que a baixa produtividade foi verificada em outras pesquisas realizadas nessa região. Ferreira et al. (2005), ao estudarem o sistema de produção de leite na microrregião de Itapetinga-Bahia, encontraram $(3,8 \mathrm{~L} / \mathrm{vaca} / \mathrm{dia})$ valores um pouco superiores ao desta pesquisa que, segundo os autores, deve-se ao fato desses municípios da região estarem localizados em uma área agropastoril, com forte tradicionalismo da pecuária de corte extensiva.

Entretanto, quando comparados com os resultados apresentados por Ferrão (2000), que observou 10,48L/vaca/dia na região de Pedro Leopoldo- Minas Gerais, os valores encontrados na região sudoeste da Bahia, para produtividade leiteira, são baixos. Essa diferença na produtividade pode estar associada às técnicas de melhoramento genético que têm sido aplicadas em Minas Gerais, diferente do que ocorre no sudoeste da Bahia, onde são exploradas vacas não especializadas com baixa aptidão leiteira. Segundo Grossi \& Freitas (2002), o aumento da produtividade em sistemas leiteiros, mediante melhoramento dos índices técnicos e econômicos, é fundamental tanto para a sobrevivência dos produtores na atividade, quanto para a oferta de produtos mais competitivos e de melhor qualidade ao mercado.

Outro fator que deve ser considerado é a alimentação, pois, a principal fonte de alimento do rebanho dessa região é baseada na utilização dos pastos naturais, cujo potencial forrageiro está diretamente relacionado com o manejo a que são submetidos e com sua adaptação às condições locais de solo e clima. Nessa acepção, devem-se adotar estratégias de manejo do pastejo dos animais, de acordo com os pastos em cada época do ano, pois estes, quando manejados corretamente, favorecem o vigor e a produtividade das plantas forrageiras, $\mathrm{o}$ que afeta positivamente a produção e o desempenho animal.

Em outra pesquisa realizada na cidade de Itagiba, na região sul da Bahia, Barreto et al. (2007), em estudo do sistema de produção de leite em uma associação composta por 17 propriedades, observaram uma produtividade de 2,02L/vaca/dia nas pequenas propriedades e 1,69L/vaca/dia nas médias propriedades. Os autores atribuíram essa baixa produtividade à base genética do rebanho, que consiste em raças não especializadas. A comparação desses resultados entre municípios que compõem regiões do mesmo estado mostra que a região do sudoeste baiano, para este parâmetro avaliado, apresenta resultados ligeiramente superiores. Vale ressaltar, entretanto, que houve pequenos incrementos na produção leiteira nos últimos anos na região, havendo, portanto a necessidade de melhorá-la por meio da implantação de programas continuados de assistência técnica envolvendo as agroindústrias de leite e as propriedades leiteiras a elas associadas. Esse benefício tem chegado através de programas do governo e de iniciativas particulares que promovem a educação do homem do campo, fomentam o crescimento do agronegócio e o desenvolvimento socioeconômico dos produtores rurais.

Conclui-se que os principais fatores que limitam a eficiência dos sistemas de produção do leite da região sudoeste da 
Rev. Bras. Saúde Prod. Anim., Salvador, v.13, n.3, p.825-837 jul./set., 2012 http://www.rbspa.ufba.br ISSN 15199940

Bahia estão relacionados ao inadequado manejo sanitário, reprodutivo e alimentar, o que favorece a baixa produtividade animal, bem como a baixa aptidão leiteira do rebanho e o baixo nível tecnológico aplicado.

É necessário estimular ações de políticas públicas bem planejadas, de modo a possibilitar o desenvolvimento tecnológico e definir um novo panorama de ações estratégicas para fortalecer o setor da pecuária leiteira na região sudoeste da Bahia, com o intuito de sanar as deficiências encontradas e aumentar o potencial da produção leiteira do rebanho.

\section{REFERÊNCIAS}

AMARAL, L.A.; ROMANO, A.P.M.; NADER FILHO, A.; ROSSI JÚNIOR, O.D. Qualidade da água em propriedades leiteiras como fator de risco à qualidade do leite e à saúde da glândula mamária. Arquivo do

Instituto de Biologia, v.71, n.4, p.417421, 2004.

AZEVEDO, R.A.; FELIX, T.M.; PIRES JÚNIOR, O.S.; ALMEIDA, A.C.; DUARTE, E.R. Perfil de propriedades leiteiras ou com produção mista no norte de minas gerais. Revista

Caatinga, v.24, n.1, p.153-159, 2011.

BARRETO, D.; NUNES, L.R.; FERNANDES, S.A.A.; PEDREIRA, M.S.; MUNIZ, L.M.S.; ALMEIDA, J.L.N.; DUARTE, R.A.B.; FREITAS, M.A.; MATARAZZO, S.V.

Caracterização estruturais dos sistemas de produção de leite dos produtores ligados à associação de produtores de leite de Itagiba-Bahia. Revista do Instituto de Laticínios "Candido Tostes”, v.62, n.357, p.451-458, 2007.
EMBRAPA. Sistema de produção.

Disponível em:

$<$ http://sistemasdeproducao.cnptia.em

brapa.br>. Acesso em: 20 fev.2011.

FERNANDES, S.A.A.; FALEIRO, A.S.; FERRÃO, S.P.B.; VIEIRA, V.F.; SOUZA, D.R.; NUNES, L.R.; SANTOS, N.B.L.; FERRÃO, I.S.; PEREIRA, M.M.; FREITAS, M.A.; MATARAZZO, S.V. Perfil tecnológico de sistemas de produção de leite resfriado. Revista Brasileira de Saúde e Produção Animal [Online], v.13, n.1, p.1-12, 2012.

FERRÃO, I.S. A produção de leite e o profissional veterinário na percepção dos produtores de leite de Pedro Leopoldo. 2000. 42p.

Dissertação (Mestrado) - Universidade Federal de Minas Gerais, Belo Horizonte.

FERREIRA, H.F.; PIRES, A.J.V.; MOTA, J.A. Produção leiteira na microrregião de Itapetinga, Bahia: aspectos sócioeconômicos. Revista Eletrônica de Veterinária, v.6, n.7, p.1-14, 2005.

GROSSI, S.F.; FREITAS, M.A.R.

Eficiência reprodutiva e produtiva em rebanhos leiteiros comerciais monitorados por sistema informatizado. Revista Brasileira de Zootecnia, v.31, n.3, p.1362-1366, 2002. Supl.

LUIZ, A.J.B.; SILVEIRA, M.A. Diagnóstico rápido e dialogado em estudos de desenvolvimento rural sustentável. Pesquisa Agropecuária Brasileira, v.35, n.1, p.83-91, 2000. 
Rev. Bras. Saúde Prod. Anim., Salvador, v.13, n.3, p.825-837 jul./set., 2012 http://www.rbspa.ufba.br ISSN 15199940

NEVES, A.L.A.; PEREIRA, L.G.R.; SANTOS, R.D.; ARAÚJO, G.G.L.; CARNEIRO, A. V.; MORAES, S.A.; SPANIOL, C.M.O.; ARAGÃO, A.S.L. Caracterização dos produtores e dos sistemas de produção de leite no perímetro irrigado de Petrolina/PE.

Revista Brasileira de Saúde e Produção Animal [Online], v.12, n.1, p.209-223, 2011.

OAIGEN, R.P.; BARCELLOS, J.O.J.; ALVES, C. O.; GRECELLÉ, R. A.; LAMPERT, V.N.; OLIVEIRA, C.M.C.; TAVARES, H.R.; SOUZA, A.C. Competitividade de sistemas de produção de bovinos de corte na Região Norte do Brasil. Revista Brasileira de Saúde e Produção Animal [Online], v.12, n.4, p.840-851, 2011.

OLIVEIRA, A.S.; CUNHA, D.N.F.V.; CAMPOS, J.M.S.; VALE, S.M.L.R.; ASSIS, A.J. Identificação e quantificação de indicadores-referência de sistemas de produção de leite.

Revista Brasileira de Zootecnia, v.36, n.2, p.507-516, 2007.

PONTES NETTO, D.; LOPES, M.O.; OLIVEIRA, M.C.S.; NUNES, M.P.; MACHINSKI JUNIOR, M.;

BOSQUIROLI, S.L.; BENATTO, A.; BENINI, A.; BOMBARDELLI, A.L.C, VEDOVELLO FILHO, D.;

MACHADO, E.; BELMONT, I.L.; ALBERTON, M.; PEDROSO, P.P.; SCUCATO, E.S. Levantamento dos principais fármacos utilizados no rebanho leiteiro do Estado do Paraná.

Acta Scientiarum. Animal Sciences, v.27, n.1, p.145-151, 2005.
SECRETARIA DA AGRICULTURA, IRRIGAÇÃO E REFORMA AGRÁRIA - SEAGRI. Produção de leite na Bahia. Disponível: <www.seagri.ba.gov.br/noticias.asp?qac $\mathrm{t}=$ view\&exibir=clipping\&notid=21997. Acesso em: 08 nov. 2010.

SUPERINTENDÊNCIA DE ESTUDOS ECONÔMICOS E SOCIAIS DA BAHIA - SEI. Informações municipais. Disponível em: <http://www.sei.ba.gov.br>. Acesso em: 10 nov. 2010.

TEIXEIRA, R.M.A.; LANA, R.P.; FERNANDES, L.O.; OLIVEIRA, A.S.; QUEIROZ, A.C.; PIMENTEL, J.J.O.

Desempenho produtivo de vacas da raça Gir leiteira em confinamento alimentadas com níveis de concentrado e proteína bruta nas dietas. Revista Brasileira de Zootecnia, v.39, n.11, p.2527-2534, 2010.

WINCK, C.A.; THALER NETO, A. Perfil de propriedades leiteiras de Santa Catarina em relação à Instrução Normativa 51. Revista Brasileira de Saúde e Produção Animal [Online], v.13, n.2, p.296-305, 2012.

ZANELA, M.B.; FISCHER, V.; RIBEIRO, M.E.R.; STUMPF JR, W.; ZANELA, C.; MARQUES, L.T.; MARTINS, P.R.G. Qualidade do leite em sistemas de produção na região Sul do Rio Grande do Sul. Pesquisa Agropecuária Brasileira, v.41, n.1, p.153-159, 2006.

Data de recebimento: 20/09/2011 Data de aprovação: 01/08/2012 